\title{
Contribuição da Avaliação Radiológica no Hiperparatireoidismo Secundário
}

\author{
Radiology Contribution for the Evaluation \\ of Secondary Hyperparathryroidism
}

\author{
Fabiano Nassar de Castro Cardoso ${ }^{(1)}$, Matiko Yanaguizawa ${ }^{(1)}$, Gustavo S. Taberner ${ }^{(1)}$, \\ Édson S. Kubota ${ }^{(1)}$, Artur da Rocha Corrêa Fernandes ${ }^{(1)}$, Jamil Natour $^{(2)}$
}

\section{INTRODUÇÃO}

A osteodistrofia renal é um termo geral que engloba todos os distúrbios do metabolismo do fosfato e do cálcio que acabam por produzir uma ampla variedade de anormalidades ou complicações no sistema musculoesquelético decorrentes da própria deterioração da função renal ${ }^{(1,2)}$ ou de seu tratamento ${ }^{(3)}$.

A incidência de tais complicações, de maneira geral, tem diminuído nos últimos anos principalmente em virtude do uso rotineiro de exames laboratoriais com dosagens do cálcio sérico ${ }^{(4)}$.

O hiperparatireoidismo secundário se caracteriza por alterações na remodelação óssea, dando origem à lesão clássica conhecida como osteíte fibrosa cística, que é um estado de alto turnover ósseo caracterizado por aumento das atividades osteoclástica e osteoblástica, bem como por fibrose medular peritrabecular ${ }^{(5)}$.

A deficiência de $1,25(\mathrm{OH})_{2}$ vitamina $\mathrm{D}$, a intoxicação por alumínio, a hipocalcemia e a acidose metabólica podem resultar em mineralização deficiente da matriz osteóide com decorrente raquitismo, se ocorrer no esqueleto imaturo, ou osteomalacia, se ocorrer no esqueleto maduro ${ }^{(2,6)}$.

Além disso, como resultado do maior nível plasmático do produto cálcio-fosfato, ocorre a deposição de diferentes compostos de cálcio e fosfato em partes moles e cristais de hidroxiapatita de cálcio em órgãos, o que é conhecido como calcificação metastática ${ }^{(2,6)}$.

As alterações no turnover ósseo podem resultar ainda em osteopenia ou osteoporose e osteoesclerose ${ }^{(2)}$.
Como complicações da hemodiálise e do transplante renal podem ocorrer depósito de proteína amilóide, espondiloartropatia destrutiva, osteonecrose e infecções musculoesqueléticas ${ }^{(2)}$.

Apesar de o padrão-ouro para o diagnóstico da osteodistrofia renal ainda ser a biópsia óssea e de novos métodos de medida da densidade óssea estarem disponíveis ${ }^{(7)}$, a radiografia convencional representa, até o momento, importante e amplamente disponível ferramenta diagnóstica ${ }^{(2)}$.

\section{ALTERAÇÕES RELACIONADAS AO HIPERPARATIREOIDISMO}

\section{REABSORÇÃO ÓSSEA}

Em virtude da maior atividade osteoclástica, podemos ter reabsorção óssea que, embora possa ocorrer em diferentes locais do esqueleto, como crânio, articulações sacroilíacas, margem distal da clavícula, entre outros, ocorre mais comumente nas mãos ${ }^{(6)}$. A reabsorção óssea pode ser subperiosteal, intracortical, endosteal, subcondral, subligamentar ou subtendínea.

Já foi comprovado que o local mais precoce em que observamos reabsorção óssea subperiosteal é a falange média do segundo e terceiro dedos, em seu aspecto radial, servindo também para monitorarmos os efeitos do tratamento do hiperparatireoidismo secundário (Figuras la e lb). Porém, para demonstrarmos alterações ósseas discretas pode ser necessária a utilização de filmes mamográficos, radiografias digitalizadas ou magnificações focais ${ }^{(2)}$.

1. Departamento de Diagnóstico por Imagem da Universidade Federal de São Paulo (Unifesp).

2. Disciplina de Reumatologia da Unifesp.

Endereço para correspondência: Artur da Rocha Corrêa Fernandes, DDI/Unifesp, Rua Botucatu, 740, CEP 04023-900, São Paulo, SP, Brasil, e-mail: artur_personal@yahoo.com.br 

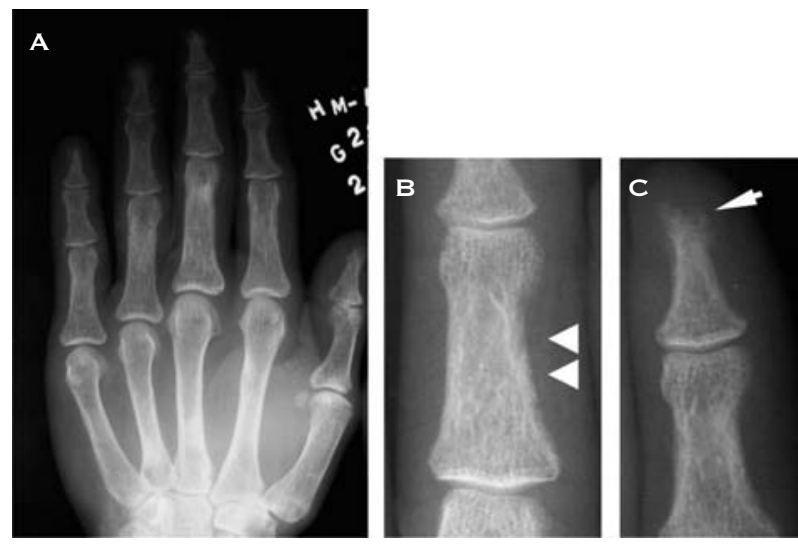

Figura 1a - Radiografia em AP da mão de um paciente de 48 anos com hiperparatireoidismo secundário. $1 \mathrm{~b}$ - Radiografia localizada mostrando os sinais de reabsorção subperiosteal (pontas de seta) no aspecto radial da falange média do 2 o dedo. 1c - Radiografia localizada do mesmo paciente indicando reabsorção subperiosteal da falange distal do dedo, acro-osteólise, com perda da definição do córtex periférico (seta branca).

Inicialmente, a reabsorção subperiosteal produz perda da definição da superfície cortical que, com a progressão da doença, pode levar ao desaparecimento cortical completo. Se as erosões não estiverem presentes nas falanges, é muito improvável que outras áreas de reabsorção óssea possam ser radiograficamente identificadas em outros locais do esqueleto.

Reabsorções nas falanges distais dos dedos em fases mais avançadas podem resultar em acro-osteólise (Figura 1), com separação completa da extremidade distal da falange de sua porção mais proximal. Com o tratamento adequado, essas áreas regridem, podendo, porém, restar algum grau de deformidade residual ${ }^{(6)}$.

Outro sinal radiográfico precoce no hiperparatireoidismo secundário é o desaparecimento da lâmina dura que circunda as raízes dos dentes ${ }^{(8)}$.

Como referido anteriormente, outros locais freqüentemente afetados no hiperparatireoidismo secundário com reabsorção óssea podem ser áreas justa-articulares das pequenas articulações das mãos e dos pés, articulações acromioclavicular, esternoclavicular e sacroilíacas, além da sínfise púbica ${ }^{(2)}$.

Quando a reabsorção subcondral envolve as articulações sacroilíacas, promovendo aumento do espaço articular, e a reabsorção subligamentar ocorre nas tuberosidades isquiáticas, é importante que se faça o diagnóstico diferencial com a espondilite anquilosante ${ }^{(3)}$.

A reabsorção subperiosteal pode se somar à reabsorção osteoclástica dentro dos canais de Havers, com formação de pequenos túneis intracorticais. Ao se somar com a reabsorção endosteal, podemos notar pequenos recortes no contorno interno do córtex ósseo.

$\mathrm{Na}$ doença avançada, a reabsorção trabecular pode levar à perda de definição e da textura do osso esponjoso, e o local maic tínicn em nue esca alteracão node cer nhservada é no crânio, com o aspecto referido de "sal e pimenta" (Figuras 2a e 2b).
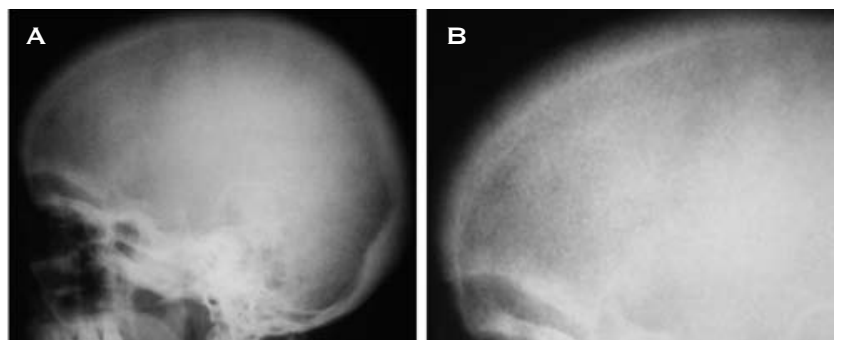

Figura 2a - Radiografia em perfil de crânio com padrão em "sal e pimenta" mostrando o padrão de reabsorção trabecular óssea dentro da díploe e perda da definição da tábua externa. 2b - Imagem localizada evidenciando melhor o padrão em "sal e pimenta".

Já a reabsorção subligamentar e subtendínea pode ocorrer em uma série de locais, mais comumente nas tuberosidades isquiáticas, trocanteres femorais (Figuras $3 \mathrm{a} \mathrm{e}$ 3b) e inserções dos ligamentos coracoclaviculares ${ }^{(2)}$.

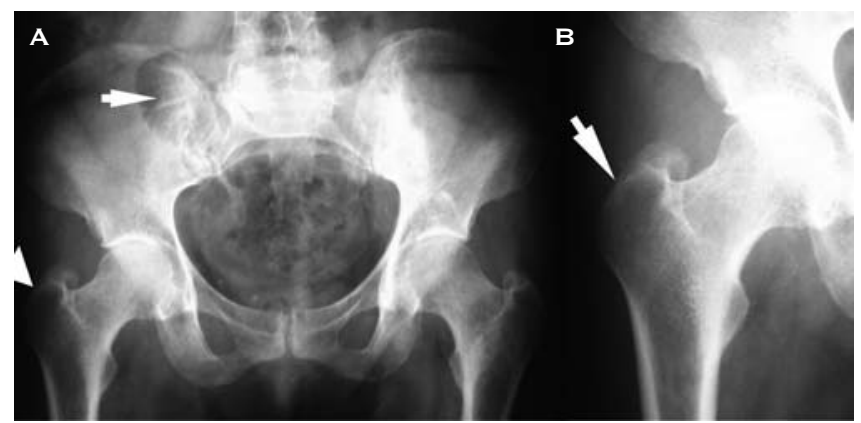

Figura 3a - Radiografia em AP da bacia de paciente com hiperparatireoidismo exibindo um padrão de reabsorção subcondral na articulação sacroilíaca direita (seta branca) e também reabsorção subtendínea no trocanter maior homolateral (ponta de seta). $3 b$-Radiografia realizada três anos depois, mostrando melhora na reabsorção subtendínea (seta) com a normalização dos níveis de cálcio sérico.

\section{NEOFORMAÇÃO ÓSSEA}

Neoformação óssea periosteal também pode ser observada em pacientes com hiperparatireoidismo secundário, podendo afetar os metatarsos, metacarpos, falanges, fềmur, úmero, rádio e ulna. Uma zona hipertransparente entre o osso periosteal neoformado e o córtex subjacente pode ser observada. 
Quanto à osteoesclerose, pode ser causada por acúmulo de matriz osteóide escassamente mineralizada, que radiograficamente aparece mais densa do que o osso normal, ou pode ser decorrente de uma resposta osteoblástica exagerada seguindo a reabsorção óssea.

Tal aumento na densidade óssea pode ser generalizado ou mais freqüentemente localizado no esqueleto axial, no qual se observa esclerose dos planaltos vertebrais com a manutenção da densidade óssea normal em sua porção média, conferindo a esta o aspecto típico de "vértebra em camisa de rúgbi" (Figuras 4a e 4b) ${ }^{(6)}$.
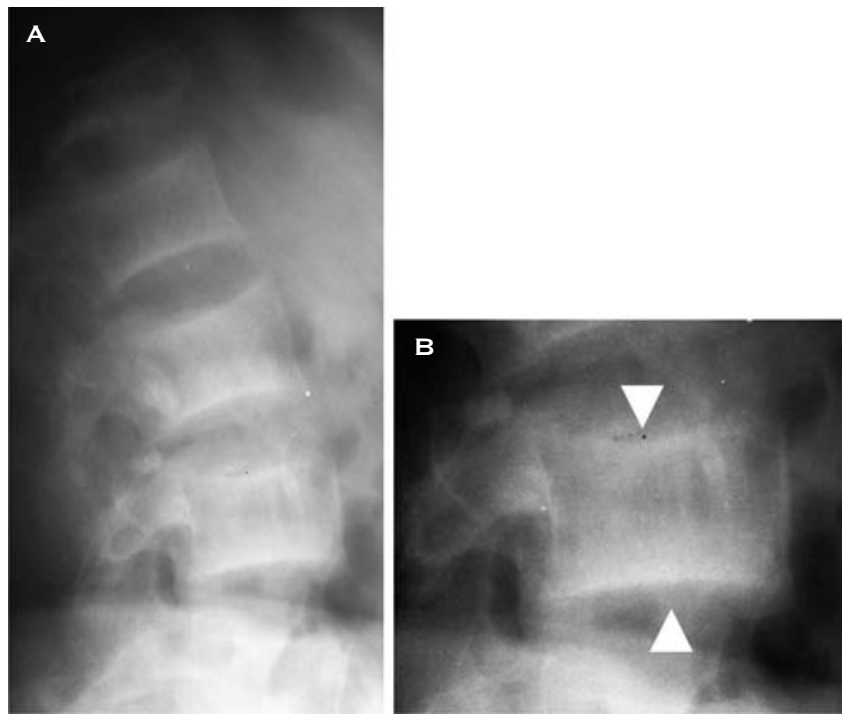

Figura $4 a$ - Vértebra em "camisa de rúgbi". 4b - 0steosclerose (pontas de seta) logo abaixo dos planaltos vertebrais com preservação da densidade normal de sua porção média.

\section{TUMOR MARROM (OSTEOCLASTOMA)}

O tumor marrom é reconhecido como sendo um processo reativo não-neoplásico devido a reabsorção óssea e lesão óssea localizada ${ }^{(9)}$.

Seu nome deriva de seu aspecto marrom-avermelhado decorrente de micro-hemorragias e deposição de hemossiderina ${ }^{(8,9)}$.

Ocorre mais freqüentemente em costelas, mandíbula, clavícula e pelve, e mais raramente no crânio ${ }^{(10)}$.

Histologicamente, apresenta estroma fibroblástico bastante vascularizado, com numerosas células gigantes multinucleadas semelhantes a osteoclastos ${ }^{(8)}$.

Radiologicamente, caracteriza-se como lesões líticas, bem definidas, que expandem ou erodem o osso afetado, podendo simular uma neoplasia primária óssea ou lesão metastática (Figuras $5 \mathrm{a}$ e $5 \mathrm{~b})^{(8-10)}$.
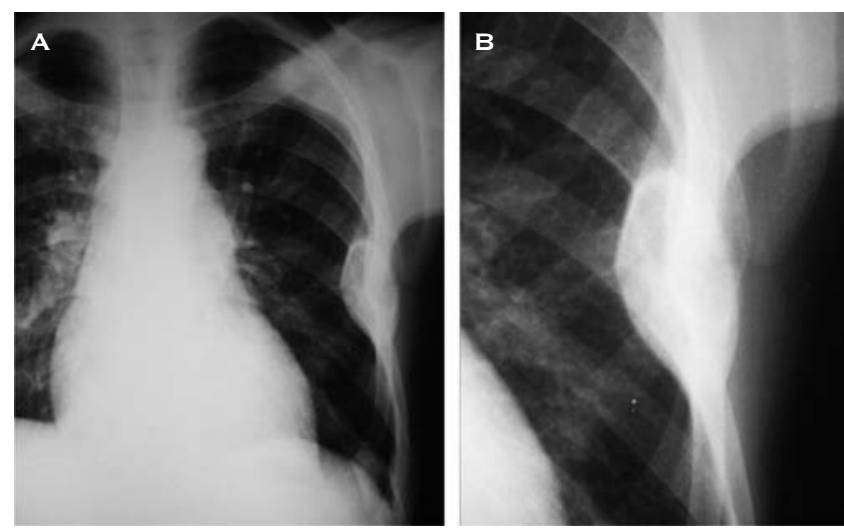

Figuras 5a e 5b - Radiografias de tórax AP e localizada demonstrando lesões líticas, expansivas (tumores marrons) nas porções ântero-laterais das costelas esquerdas.

Seu aspecto, na ressonância magnética $(\mathrm{RM})$, reflete as características patológicas do tumor marrom. Dessa forma, a proporção relativa de hemossiderina, focos hemorrágicos, áreas císticas e de estroma fibroso explica sua intensidade de sinal variável, de baixo sinal a hipersinal, nas seqüências ponderadas em T2. Além disso, seu realce intenso e precoce em imagens dinâmicas pós-contraste ponderadas em Tl parece ser decorrente de sua marcante vascularização ${ }^{(8)}$.

Na maior parte dos casos, a correção do hiperparatireoidismo leva à significativa regressão ou até desaparecimento completo do tumor marrom ${ }^{(9)}$. Entretanto, quando são grandes, sintomáticos ou têm risco de fratura patológica, a ressecção cirúrgica deve ser considerada ${ }^{(8)}$.

\section{RAQUITISMO E OSTEOMALACIA}

A deficiência de $1,25(\mathrm{OH})_{2}$ vitamina $\mathrm{D}$ resulta em mineralização deficiente da matriz osteóide, levando a uma anormalidade qualitativa do osso, com decorrente osteomalacia ou raquitismo $^{(2)}$.

O raquitismo é caracterizado por falha ou retardo na calcificação da placa de crescimento em crianças cujas epífises ainda não fundiram. Assim, é uma doença que afeta primariamente a calcificação endocondral, que se manifesta clínica e radiologicamente por alargamento e deformidades nas regiões metafisárias dos ossos longos ${ }^{(11)}$. Essas alterações são mais óbvias em locais de maior desenvolvimento, particularmente punhos, joelhos, porções anteriores das costelas ("rosário raquítico") e membros inferiores, com $\mathrm{o}$ arqueamento destes ${ }^{(2)}$.

Já a osteomalacia, que acomete adultos e crianças com placas de crescimento já fechadas, tem como achados radiográficos clássicos as pseudofraturas ou fraturas de Milkman 
ou zonas de Looser, que ocorrem mais comumente nos ramos púbicos, margem interna do fềmur proximal, costelas, margem posterior da ulna e margem axilar da escápula ${ }^{(12)}$. Radiograficamente, aparece como uma linha hipertransparente perpendicular ao córtex ósseo, com uma margem esclerótica e que não se estende por todo o diâmetro do osso, a menos que uma fratura tenha se sobreposto a ela $(\text { Figura 6) })^{(2)}$.

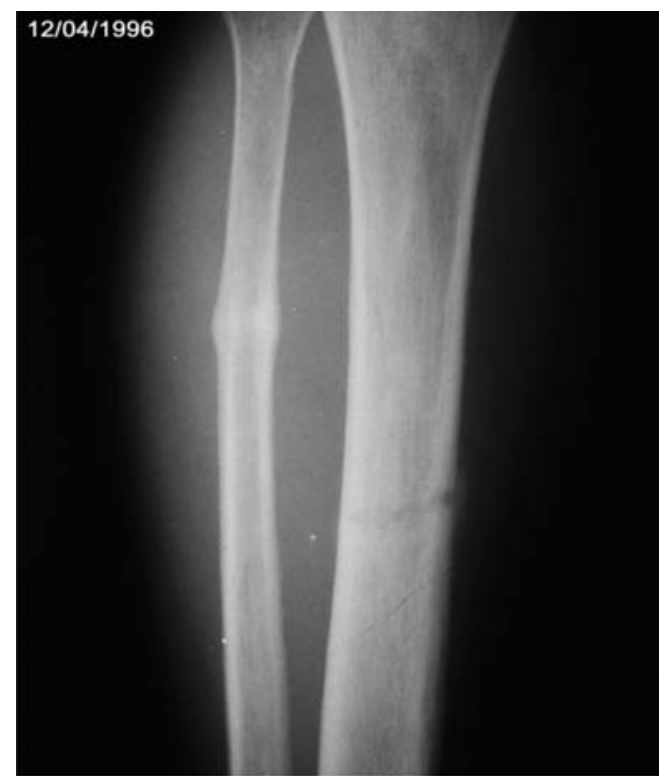

Figura 6 - Radiografia em AP da perna de um paciente com ostemalacia, evidenciando traço radiolucente, na diáfise tibial média, perpendicular ao córtex que se estende por quase toda a espessura do osso (zona de Looser). Nota-se, ainda, na porção diafisária média da fíbula, formação de calo ósseo em local de fratura prévia.

\section{OSTEOPENIA/OSTEOPOROSE}

A redução da densidade óssea na osteodistrofia renal se caracteriza radiograficamente por afilamento dos córtices e trabéculas ósseas, que são mais evidentes nas regiões mais ricas em osso esponjoso como a coluna vertebral, fêmur proximal e porção distal do antebraço.

Com o avanço do processo, podem ocorrer fraturas patológicas, e as vértebras podem adquirir formato de cunha, bicôncavo ("vértebra de peixe") (Figura 7) ou achatado.

Em virtude da baixa sensibilidade da radiografia convencional, que só permite a caracterização da osteopenia quando cerca de $30 \%$ a $40 \%$ do tecido ósseo já foi perdido, devemos dispor de métodos mais sofisticados para a mensuração da densidade óssea, como a densitometria ${ }^{(2)}$.

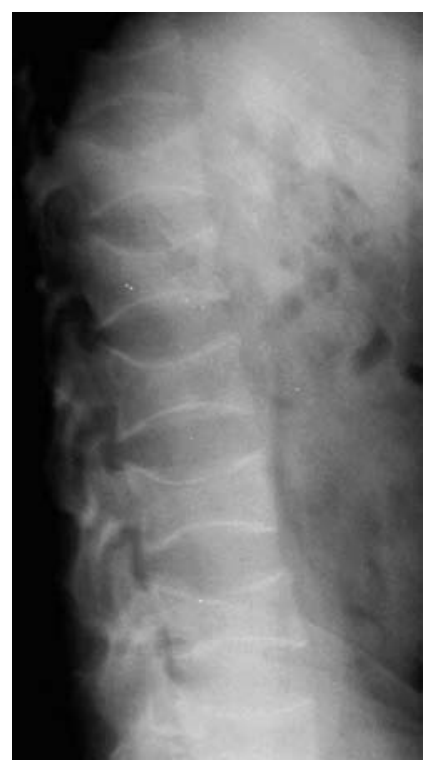

Figura 7 - Radiografia em perfil da coluna mostrando múltiplas fraturas dos corpos vertebrais, conferindo um aspecto de "vértebra de peixe".

\section{CALCIFICAÇÃO METASTÁTICA}

Resulta da deposição de fosfato de cálcio amorfo em partes moles e paredes arteriais e de cristais de hidroxiapatita em órgãos sólidos, como coração, rins, pulmões e músculos, sendo raramente detectada radiograficamente, ficando mais evidente apenas quando ocorre em vasos ou regiões periarticulares (Figura 8).

Clinicamente, essas massas calcificadas podem causar dor e edema, e crescer rapidamente, sendo facilmente confundidas com tumores ${ }^{(6)}$.

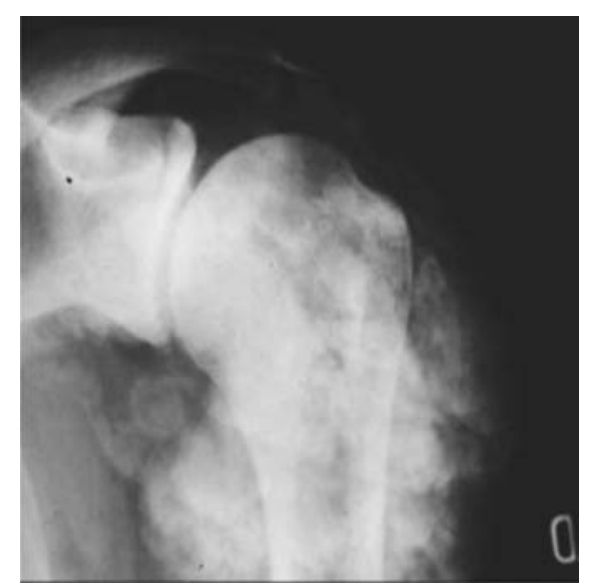

Figura 8 - Radiografia em AP do ombro de um paciente com insuficiência renal crônica, denotando extensa calcificação de partes moles periarticular. 


\section{TENDINOPATIA E ROTURA TENDÍNEA}

Tendinopatia com roturas tendíneas espontâneas ocorrem como decorrência de erosões nos locais de suas inserções, bem como do tratamento com corticosteróides após transplante renal.

Afetam mais comumente os tendões calcâneo, quadríceps e do manguito rotador ${ }^{(2,6)}$.

\section{CONCLUSÃO}

O espectro da doença óssea associada com a insuficiência renal crônica e seu tratamento (hemodiálise e transplante renal) é muito amplo e tem tido incidência decrescente nas últimas décadas em virtude da investigação laboratorial mais freqüente de possíveis alterações no metabolismo do cálcio e fosfato.

Apesar disso, o correto diagnóstico dessas entidades é de extrema relevância para que não sejam confundidas

\section{REFERÊNCIAS}

1. Oprisiu R, Hottelart C, Ghitsu S, et al.: Renal osteodystrophy (1): invasive and non-invasive diagnosis of its pathologic varieties. Nephrologie 21(5):229-37, 2000.

2. Jevtic V: Imaging of renal osteodystrophy. Eur J Radiol 46(2): 85-95, 2003.

3. Tigges S, Nance EP, Carpenter WA, Erb R: Renal osteodystrophy: imaging findings that mimic those of other diseases. AJR Am J Roentgenol 165(1):143-8, 1995.

4. Bilezikian JP: Primary hyperparathyroidism. When to observe and when to operate. Endocrinol Metab Clin North Am 29(3): 465-78, 2000.

5. Brenner BM, Rector FC: Brenner \& Rector's the kidney. $7^{\mathrm{a}}$ ed. Philadelphia, PA: Saunders, 2004.

6. Adams JE: Renal bone disease: radiological investigation. Kidney Int Suppl 73:S38-41, 1999 com lesões agressivas, como tumores ósseos primários ou metastáticos.

Além disso, mesmo com os avanços nos métodos de diagnóstico por imagem, a radiografia convencional ainda permanece como a técnica de imagem importante para a caracterização de tais alterações. $\mathrm{O}$ exame radiológico convencional permite avaliar as principais alterações relacionadas aos diferentes padrões de reabsorção óssea, áreas de osteoesclerose, manifestações de osteoporose, osteomalácia e calcificações distróficas. A ultra-sonografia é o método de escolha para a primeira abordagem de alterações de partes moles, permitindo avaliar todo espectro de alterações tendíneas. A RM raramente é empregada na rotina para avaliação das alterações relacionadas ao hiperparatireoidismo secundário.

Declaramos a inexistência de conflitos de interesse.

7. Aaron RK, Ciombor DM: Orthopedic complications of solid-organ transplantation. Surg Clin North Am86(5):1237-55, viii, 2006.

8. Takeshita T, Takeshita K, Abe S, Takami H, Imamura T, Furui S: Brown tumor with fluid-fluid levels in a patient with primary hyperparathyroidism: radiological findings. Radiat Med 24(9):631-4, 2006.

9. Kalambokis G, Economou G, Kamina S, Papachristou DJ, Bai M, Tsianos EV: Multiple brown tumors of the ribs simulating malignancy. J Endocrinol Invest 28(8):738-40, 2005.

10. Al-Gahtany M, Cusimano M, Singer W, Bilbao J, Kovacs K, Marotta T: Brown tumors of the skull base. Case report and review of the literature. J Neurosurg 98(2):417-20, 2003.

11. Pettifor JM: Rickets and vitamin D deficiency in children and adolescents. Endocrinol Metab Clin North Am 34(3):537-53, vii, 2005 .

12. Kanberoglu K, Kantarci F, Cebi D, et al.: Magnetic resonance imaging in osteomalacic insufficiency fractures of the pelvis. Clin Radiol 60(1):105-11, 2005. 